\title{
ANALISIS HUBUNGAN SISTEM MANAJEMEN KESELAMATAN DAN KESEHATAN KERJA TERHADAP TINGKAT KECELAKAAN PADA PROYEK
}

\author{
Andi Lay Wirawan ${ }^{1}$ dan Mega Waty ${ }^{2}$ \\ ${ }^{1}$ Program Studi Sarjana Teknik Sipil, Universitas Tarumanagara, Jl. Letjen S. Parman No.1 Jakarta \\ Andi.325160100@stu.untar.ac.id \\ ${ }^{2}$ Program Studi Sarjana Teknik Sipil, Universitas Tarumanagara, Jl. Letjen S. Parman No.1 Jakarta \\ mega@ft.untar.ac.id
}

Masuk: 18-07-2020, revisi: 30-08-2020, diterima untuk diterbitkan: 02-11-2020

\begin{abstract}
The construction industry in general can be categorized as activities that contain a lot of elements of danger and very risky for accidents. Occupational safety and health management system (SMK3) is the one of factors in a construction project. Implementation of "SMK3" needs to do to provide a good, safe and comfortable working environment, but it is also useful for avoiding work accidents. This study aims to determine the relationship between the factors of the application of "SMK3" to the level of accidents whether correlated or not, so we get the factors that apply the safety management system and work health which is most related to the accident rate. The research method used is quantitative descriptive method, namely by distributing questionnaires that have been prepared previously. Then the data processing is done with the help of an applied program to obtain the results of the validity test, reliability test, normality test and correlation results using the Pearson Product Moment method. The results of the Pearson Product Moment correlation analysis produced 14 variables that correlated with the accident rate with the most influential factor being the availability of danger signs on the project.
\end{abstract}

Keywords: occupational safety and health management system; accident rate; pearson product moment

\begin{abstract}
ABSTRAK
Industri kontruksi pada umumnya dapat dikategorikan sebagai kegiatan yang banyak mengandung unsur bahaya dan sangat berisiko untuk terjadinya kecelakaan. Sistem manajemen keselamatan dan kesehatan kerja merupakan salah satu faktor utama dalam suatu pelaksanaan proyek konstruksi. Penerapan SMK3 perlu dilakukan untuk memberikan suasana lingkungan kerja yang baik, aman, dan nyaman, selain itu juga berguna untuk menghindari kecelakaan kerja. Penelitian ini memiliki tujuan mengetahui hubungan faktor penerapan sistem manajemen keselamatam dan kesehatan kerja terhadap tingkat kecelakaan apakah berkorelasi atau tidak, sehingga didapatkan faktor penerapan SMK3 yang paling berhubungan dengan tingkat kecelakaan. Metode penelitian yang digunakan adalah dengan metode diskriptif kuantitatif yaitu dengan penyebaran kuesioner yang sudah disiapkan sebelumnya. Lalu pengolahan data dilakukan dengan bantuan program terapan untuk didapatkan hasil uji validitas, uji reliabilitas, uji normalitas dan hasil korelasi dengan menggunakan metode pearson product moment. Hasil dari analisis korelasi pearson product moment menghasilkan 14 variabel yang berkorelasi terhadap tingkat kecelakaan dengan faktor yang paling berpengaruh adalah ketersediaan rambu-rambu tanda bahaya pada proyek.
\end{abstract}

Kata Kunci: sistem manajemen keselamatan dan kesehatan kerja; tingkat kecelakaan; pearson product moment

\section{PENDAHULUAN}

Salah satu bidang yang paling berisiko terhadap kesalamatan pekerjanya di dalam lapangan ialah proyek konstruksi. Organisasi Perburuhan Internasional (ILO, 2011) pernah menyatakan bahwa tempat konstruksi merupakan 1 dari 6 kecelakaan fatal yang ada di tempat kerja. Ancaman terhadap keselamatan pekerja di tempat konstruksi antara lain: terjebak diantara reruntuhan bangunan, jatuh dari tempat tinggi, tertabrak oleh alat berat atau kendaraan proyek, tersengat oleh aliran listrik, terkena benda yang jatuh, terpapar panas atau api, beracun, berbahaya (Consultnet Ltd., 2011). Beberapa hal yang dapat disebabkan dari kecelakaan kerja antara lain, hilangnya produktivitas, terganggunya jadwal pekerjaan, kerusakan sarana dan prasarana proyek, dan masih banyak lagi yang mengganggu proses konstruksi secara keseluruhan. 
Pada industri kontruksi pada umumnya dapat dikategorikan sebagai kegiatan yang banyak mengandung unsur bahaya. Dibutuhkan stamina yang fit dan juga prima dari para pekerjanya karena situasi di dalam proyek konstruksi dapat digambarkan sebagai sebuah karakter yang keras dan juga kegiatannya kompleks. Tingginya tingkat kecelakaan kerja salah satunya disumbangkan oleh pekerjaan proyek konstruksi. Tingginya kasus kecelakaan kerja dapat menyebabkan banyak sekali kerugian untuk berbagai pihak, seperti kontraktor, owner, dan yang paling dirugikan tentu saja pekerja itu sendiri.

Kurangnya implementasi dari penerapan program sistem manajemen keselamatan dan kesehatan kerja (SMK3) perusahaan dapat dikatakan sebagai penyebab utama dari tingginya tingkat kecelakaan di dalam proyek konstruksi, dibandingkan dengan kesadaran yang rendah dari pekerja tentang keselamatan dan kesehatan kerja (K3). Maka dari itu, evaluasi penerapan SMK3 sangatlah penting untuk dilakukan guna menekan dan mengendalikan tingkat kecelakaan di proyek konstruksi.

Untuk memberikan suasana lingkungan kerja yang baik, aman, dan nyaman perlu dilakukan penerapan SMK3, selain itu juga berguna untuk menghindari kecelakaan kerja, tetapi usaha pemerintah untuk menghindari kecelakaan kerja melalui Undang-undangnya akan sia-sia tanpa adanya implementasi SMK3 dari perusahaan atau kontraktor dan juga kesadaran pekerja tentang pentingnya K3 itu sendiri.

Bisa dikatakan elemen inti dari keberhasilan penerapan SMK3 adalah komitmen perusahaan itu sendiri. Selain elemen inti tersebut, ada juga beberapa elemen yaitu berbagai proses yang terintegrasi dengan sistem manajemen lain yang terdapat diperusahaan guna menciptakan lingkungan kerjan yang baik, aman, dan nyaman bagi pekerja. Berdasarkan latar belakang yang sudah disebutkan sebelumnya, maka rumusan masalah pada penelitian ini adalah bagaimana hubungan faktor-faktor penerapan Sistem Manajemen K3 terhadap tingkat kecelakaan kerja pada proyek konstruksi gedung bertingkat dan faktor SMK3 apa yang paling berhubungan dengan tingkat kecelakaan?

Tujuan dari penelitian ini adalah mengetahui hubungan faktor-faktor penerapan Sistem Manajemen K3 terhadap tingkat kecelakaan kerja pada proyek konstruksi Gedung bertingkat dan faktor SMK3 apa yang paling berhubungan dengan tingkat kecelakaan .

Batasan masalah pada penelitian ini ada tiga, yaitu:

1. Penelitian ini dilakukan pada proyek konstruksi gedung di Jakarta dan Makassar.

2. Objek pada penelitian ini adalah pekerja dan staff pada proyek konstruksi gedung di Jakarta dan Makassar.

3. Penelitian dilakukan dengan menyebarkan pertanyaan pada kuesioner yang telah penulis siapkan.

\section{Bangunan gedung}

Bangunan adalah wujud fisik hasil pekerjaan konstruksi yang menyatu dengan tempat kedudukan baik yang diatas atau dibawah tanah dan menyatu dengan tempat kedudukan di air (Ariestadi, 2008).

\section{Kecelakaan kerja}

Menurut Peraturan Menteri Tenaga Kerja Nomor 03/Men/98, kecelakaan kerja adalah suatu kejadian yang tidak dikehendaki dan tidak diduga semula yang dapat menimbulkan korban manusia dan atau harta benda. Sedangkan menurut Heinrich et al., (1980), kecelakaan kerja merupakan peristiwa berpotensi dan dapat menyebabkan kerusakan pada alam atau lingkungan,. Disamping itu, kecelakaan kerja merupakan sebuah peristiwa yang tidak bisa direncanakan atau tidak dapat terkendali akibat dari sebuah reaksi suatu orang, bahan, atau objek yang dapat mengakibatkan cidera atau kemungkinan lainnya. Kecelakaan tidak hanya selalu menyebabkan cidera berupa lukaluka, namun juga dapat menyebabkan kerusakan pada material konstruksi dan peralatan atau prasarana yang ada, namun kecelakaan yang menyebabkan cidera berupa luka-luka ini harus mendapatkan perhatian yang lebih besar. (Hinze, 1997)

Kecelakaan adalah sebuah kejadian yang tidak diinginkan dan diluar kontrol manusia, dan juga menyebabkan cidera berupa luka bahkan dapat menyebabkan kematian. Bidang konstruksi merupakan salah satu bidang dimana yang pelaksanaannya memiliki resiko kecelakaan yang tinggi. Penyebab utama kecelakaan kerja pada proyek konstruksi adalah satu atau sekian hal yang memiliki hubungan dengan karakteristik proyek konstruksi yang mempunyai sifat unik, lokasi yang berbeda, terbuka, dan juga dipengaruhi cuaca, waktu pelaksaan proyek yang terbatas, dinamis serta dituntut untuk memiliki ketahanan fisik yang tinggi, juga banyak menggunakan tenaga kerja yang kurang terlatih. (Simanjuntak, 2012) 


\section{Keselamatan dan Kerja Kesehatan (K3)}

Keselamatan dan Kesehatan Kerja menurut OHSAS 18001 (2007) adalah kondisi dan faktor yang mempengaruhi atau bisa mempengaruhi keselamatan dan kesehatan pekerja (disini termasuk juga pekerja kontrak dan kontraktor) dan juga pengunjung ataupun orang lain yang berada di lokasi kerja.

Sedangkan secara filosofis, kesehatan dan keselamatan berarti suatu pemikirian dan juga suatu upaya untuk menjamin utuhnya jasmani maupun rohani dari pekerja (pada khususnya) dan juga pada manusia (pada umumnya), hasil karya dan juga budaya menuju masyarakat yang adil dan juga makmur.

\section{Sistem Manajemen Keselamatan dan Kesehatan Kerja (SMK3)}

Sistem Manajemen Keselamatan dan Kesehatan Kerja (SMK3) merupakan tata kelola dari adanya jaminan atas keselamatan dan kesehatan kerja bagi pekerja agar mereka semua bekerja secara aman dan juga nyaman dalam melaksanakan pekerjaannya, sehingga mereka dapat bekerja secara konsentrasi penuh dan mampu bekerja secara produktif.

\section{METODE PENELITIAN}

\section{Metode pengumpulan data}

Data yang dikumpulkan merupakan data primer dan data sekunder.

\section{a. Data Primer}

Data primer yang dilakukan adalah dengan studi lapangan dengan cara survey kepada pihak terkait melalui pendekatan, yaitu dengan menyebarkan kuesioner dan melakukan wawancara.

b. Data Sekunder

Data sekunder merupakan data yang diperoleh berdasarkan sumber yang sudah ada sebelumnya.

\section{Lokasi proyek}

Lokasi proyek yang akan digunakan dalam penelitian adalah proyek konstruksi gedung yang berlokasi di Jakarta dan Makassar.

\section{Variabel penelitian}

Pengumpulan data yang digunakan dalam penelitian ini salah satunya dengan menggunakan pengumpulan data yang bersifat kuantitatif, dan salah satu jenis data yang dikumpulkan adalah data primer dengan menyebarkan kuesioner kepada sejumlah responden. Variabel yang digunakan dalam penyusunan kuesioner ini ada dua, yaitu variabel penerapan SMK3 dan juga variabel tingkat kecelakaan. Variabel penerapan SMK3 yang peneliti tentukan yaitu faktor perencanaan, penerapan, dan evaluasi dalam sistem manajemen kesehatan dan keselamatan kerja.

Variabel yang akan digunakan dalam penelitian ini diambil dari beberapa sumber dan akan dibagi menjadi tiga bagian, yaitu perencanaan SMK3, pelaksanaan dan penerapan SMK3, dan evaluasi SMK3.

a. Perencanaan SMK3

1. Perusahaan harus memiliki buku panduan pelaksanaan K3 (Hidayat, 2011)

2. Perusahaan harus memiliki prosedur yang tepat dalam menangani kecelakaan kerja (Hidayat, 2011)

3. Perusahaan memastikan semua pekerja memiliki pengetahuan pada kebijakan K3 perusahaan (Hidayat, 2011)

4. Perusahaan harus memiliki prosedur penggunaan peralatan dan perlengkapan keselamatan kerja (Hidayat, 2011)

5. Semua pihak memastikan bahwa K3 adalah tanggung jawab bersama (Hidayat, 2011)

6. Perusahaan akan bertanggung jawab jika terjadinya kecelakaan kerja (Bramantya, 2016)

7. Pemberian reward pada pekerja yang menerapkan K3 perusahaan dengan baik (Hidayat, 2011)

8. Pemberian sanksi kepada pekerja yang melanggar atau tidak mentaati K3 perusahaan (Hidayat, 2011)

9. Perusahaan harus memberikan pelatihan K3 secara rutin (Bramantya, 2016)

10. Perusahaan harus memiliki prosedur yang tepat dalam mengidentifikasi masalah yang berhubungan dengan K3 (Bramantya, 2016)

11. Perusahaan harus menyediakan asuransi kesehatan kepada pekerja (Gunara, 2017)

12. Perusahaan memastikan pekerja bekerja pada lingkungan kerja yang aman dan nyaman (Gunara, 2017)

13. Perusahaan harus memiliki ahli K3 hukum yang memiliki lisensi ahli K3 (Gunara, 2017) 
b. Penerapan dan pelaksanaan SMK3

1. Penyediaan APD yang lengkap dan alat pemadam kebakaran (Hidayat, 2013)

2. Pekerja membuang sampah dan sisa material ke tempat sampah (Hidayat, 2011)

3. Pemeriksaan kesehatan secara berkala kepada pekerja (Hidayat, 2011)

4. Komunikasi yang baik antara staff K3 dengan para pekerja (Hidayat, 2011)

5. Penyimpanan catatan kesehatan setiap pekerja (Hidayat, 2011)

6. Mempunyai hubungan yang baik dan erat dengan pihak asuransi (Hidayat, 2011)

7. Kerja sama dengan pihak rumah sakit terkait asuransi kesehatan (Hidayat, 2011)

8. Promosi yang rutin tentang pentingnya K3 pada papan pengumuman perusahaan (Hidayat, 2011)

9. Perusahaan harus memberikan reaksi yang tepat dan cepat jika terjadi insiden atau suatu kondisi darurat (Bramantya, 2016)

10. Ketersediaan rambu-rambu tanda bahaya pada perusahaan (Gunara, 2017)

11. Perusahaan harus menginformasikan K3 terbaru pada pekerja dan pihak terkait (Gunara, 2017)

12. Inspeksi rutin staff K3 kepada para pekerja (Hidayat, 2011)

13. Pekerja merapikan prasarana dan peralatan kerja sesudah digunakan (Hidayat, 2011)

14. Alat berat dioperasikan oleh operator yang memiliki SIO (Surat Izin Operasi) dan masih berlaku (Gunara, 2017)

c. Evaluasi K3

1. Pelaksanaan rapat evaluasi K3 secara rutin (Hidayat, 2011)

2. Pencatatan insiden, kondisi atau kecelakaan kerja (Hidayat, 2011)

3. Tindakan penanggulangan kecelakaan kerja sudah dilakukan dengan baik oleh pekerja (Bramantya, 2016)

4. Memperbarui APD yang sudah usang dan tidak layak pakai. (Gunara, 2017)

5. Perusahaan harus melakukan tinjauan ulang SMK3 secara berkala (Bramantya, 2016)

6. Perusahaan selalu memiliki inovasi baru untuk meningkatkan kualitas K3 (Bramantya, 2016)

7. Perusahaan harus membuat buku catatan masa pakai APD dan menyiapkan APD pengganti bila akan habis masa pakainya (Gunara, 2017)

\section{Uji validitas}

Uji validitas yang akan digunakan dalam penelitian adalah dengan uji pearson product moment. Pengujian validitas dilakukan dengan bantuan program terapan dengan kriteria sebagai berikut :

a. Jika koefisien korelasinya (r) lebih besar dari $\mathrm{r}$ tabel, maka pernyataan pada butir dikuesioner tersebut dinyatakan valid.

b. Jika koefisien korelasinya (r) lebih kecil dari $\mathrm{r}$ tabel, , maka pernyataan pada butir dikuesioner tersebut dinyatakan tidak valid.

\section{Uji reliabilitas}

Rumus yang penulis gunakan untuk uji reliabilitas ini adalah Alpha Cronbach. Pengujian dilakukan dengan bantuan program terapan, butir pertanyaan yang sudah valid dalam uji validitas ditentukan reliabilitasnya dengan kriteria sebagai berikut :

a. Jika $\mathrm{r}$ alpha positif atau lebih besar dari $\mathrm{r}$ tabel maka pernyataan pada butir dikuesioner tersebut dinyatakan reliabel.

b. Jika $\mathrm{r}$ alpha negatif atau lebih besar dari $\mathrm{r}$ tabel, maka pernyataan pada butir dikuesioner tersebut dinyatakan tidak reliabel.

\section{Uji normalitas}

Uji normalitas yang digunakan adalah dengan metode Shapiro Wilk. Model yang dikatakan baik adalah model yang distribusi datanya normal ataupun mendekati normal. Data dapat dikatakan berdistribusi secara normal apabila memiliki nilai signifikansi yang lebih besar dari 0,05 .

\section{Analisis korelasi}

Analisis korelasi yang digunakan adalah dengan metode Pearson Product Moment. Analisis korelasi bertujuan untuk mengetahui bagaimana derajat hubungan antara variabel-variabel penerapan SMK3 dengan tingkat kecelakaan. Koefisien korelasi menunjukkan besarnya angka korelasi dan dilambangkan dengan $\mathrm{R}$.

Koefisien korelasi dapat bernilai positif dan negatif, koefisien korelasi positif yang terbesar bernilai 1, sedangkan koefisien korelasi negatif yang terbesar bernilai -1, dan yang terkecil bernilai 0. Jika koefisien korelasi bernilai 1 
berarti memiliki hubungan positif sempurna, dan jika bernilai -1 berarti memiliki hubungan negatif sempurna, dan bila bernilai 0 maka tidak memiliki hubungan/korelasi.

\section{HASIL DAN PEMBAHASAN}

\section{Pengumpulan data}

Setelah di lakukan penyebaran kuesioner yang telah dibuat dan juga dimodifikasi kepada 30 responden dibeberapa proyek konstruksi tersebut. Pemilihan responden dilakukan terhadap pekerja dan staff yang sudah ditentukan pada proyek konstruksi tersebut. Diantaranya merupakan, safety, health \& environment, site engineer, project control, $Q A Q C$ coordinator \& staff dan structure engineer. Rekap pendidikan responden dan pengalaman kerja responden dapat dilihat pada Tabel 1 dan Tabel 2.

Tabel 1. Rekap pendidikan responden

\begin{tabular}{cccc}
\hline Pendidikan & Jumlah & \% & \% kumulatif \\
\hline D3 & 5 & 16,67 & 16,67 \\
\hline S1 & 24 & 80 & 96,67 \\
\hline S2 & 1 & 3,33 & 100 \\
\hline S3 & 0 & 0 & 100 \\
\hline Total & 30 & & \\
\hline
\end{tabular}

Tabel 2. Rekap pengalaman kerja responden

\begin{tabular}{cccc}
\hline $\begin{array}{c}\text { Pengalaman } \\
\text { kerja }\end{array}$ & Jumlah & \% & $\begin{array}{c}\text { \% } \\
\text { kumulatif }\end{array}$ \\
\hline 1-2 Tahun & 14 & 46,67 & 46,67 \\
\hline 3-4 Tahun & 6 & 20 & 66,67 \\
\hline 5-6 Tahun & 4 & 13,33 & 80 \\
\hline 7-8 Tahun & 1 & 3,33 & 83,33 \\
\hline 9-10 Tahun & 1 & 3,33 & 86,67 \\
\hline >10 Tahun & 4 & 13,33 & 100 \\
\hline Total & 30 & & \\
\hline
\end{tabular}

\section{Hasil uji validitas}

Uji validitas pada penelitian ini menggunakan metode Pearson Product Moment yang dihitung menggunakan bantuan dari program terapan. Nilai hasil uji validitas telah direkap dan dapat dilihat pada tabel 3 berikut.

Tabel 3. Hasil uji validitas

\begin{tabular}{cc}
\hline Variabel & Total Score Pearson Product Moment \\
\hline X1 &, $454^{*}$ \\
X2 &, $644^{* *}$ \\
\hline X2 &, $519^{* *}$ \\
\hline X4 &, $570^{* *}$ \\
\hline X5 &, $606^{* *}$ \\
\hline X6 &, $631^{* *}$ \\
\hline X7 &, $623^{* *}$ \\
\hline X8 &, $707^{* *}$ \\
\hline X9 &, $539^{* *}$ \\
\hline X10 &, $818^{* *}$
\end{tabular}


Tabel 3. Hasil uji validitas (Lanjutan)

\begin{tabular}{|c|c|}
\hline Variabel & Total Score Pearson Product Moment \\
\hline X11 &, $440^{*}$ \\
\hline $\mathbf{X 1 2}$ & ,329 \\
\hline $\mathbf{X 1 3}$ & $426^{*}$ \\
\hline X14 &, $415^{*}$ \\
\hline $\mathbf{X 1 5}$ &, $438^{*}$ \\
\hline X16 &, $700^{* *}$ \\
\hline $\mathbf{X 1 7}$ &, 323 \\
\hline X18 &, $651^{* *}$ \\
\hline X19 &, $582^{* *}$ \\
\hline $\mathbf{X 2 0}$ &, 044 \\
\hline $\mathbf{X 2 1}$ &, $426^{*}$ \\
\hline $\mathrm{X} 22$ &, $424^{*}$ \\
\hline $\mathbf{X 2 3}$ & $448^{*}$ \\
\hline $\mathbf{X 2 4}$ & ,079 \\
\hline $\mathbf{X} 25$ & $474^{* *}$ \\
\hline X26 &, $382^{*}$ \\
\hline $\mathbf{X} 27$ & ,321 \\
\hline $\mathbf{X} 28$ &, $599^{* *}$ \\
\hline $\mathbf{X 2 9}$ &, $621^{* *}$ \\
\hline $\mathbf{X 3 0}$ & $644^{* * *}$ \\
\hline X31 &, $577^{* *}$ \\
\hline $\mathbf{X 3 2}$ &, $643^{* * *}$ \\
\hline X33 &, $585^{* *}$ \\
\hline X34 &, $414^{*}$ \\
\hline Total & 1 \\
\hline
\end{tabular}

Hasil uji validitas yang tertera pada tabel 3 kemudian akan dibandingkan nilai $r$ hitungnya nya dengan $r$ tabel. $r$ tabel didapat dari jumlah responden, karena jumlah responden pada penelitian ini 30 maka nilai $r$ tabelnya adalah 0,361 . Berdasarkan tabel 3 variabel yang memiliki nilai $r$ hitung > dari $r$ tabel adalah $\mathrm{X} 1, \mathrm{X} 2, \mathrm{X} 3, \mathrm{X} 4, \mathrm{X} 5, \mathrm{X} 6, \mathrm{X} 7, \mathrm{X} 8, \mathrm{X} 9$, X10, X11, X13, X14, X15, X16, X18, X19, X21, X22, X23, X25, X26, X28, X29, X30, X31, X32, X33, dan X34. Maka dari itu, bisa ditarik kesimpulan terdapat 29 variabel yang $r$ hitungnya $>r$ tabel yang berarti butir pernyataan tersebut valid. Sedangkan terdapat $r$ hitung yang nilainya < $r$ tabel yaitu X12, X17, X20, X24, dan X27, ini berarti variabel-variabel tersebut tidak valid dan dihapus kemudian dilakukan pengujian ulang.

\section{Hasil uji reliabilitas}

Uji reliabilitas pada penelitian ini menggunakan metode Alpha Cronbach yang dihitung menggunakan bantuan dari program terapan. Hasil uji reliabilitas telah direkap dan dapat dilihat pada tabel 4 berikut. 
Tabel 4. Hasil uji reliabilitas

\begin{tabular}{cr}
\multicolumn{2}{c}{ Reliability statistics } \\
\hline $\begin{array}{c}\text { Cronbach's } \\
\text { alpha }\end{array}$ & Nof \\
items \\
,918 & 29 \\
\hline
\end{tabular}

Nilai Cronbach Alpha yang didapat dari analisis menggunakan program terapan adalah sebesar 0,918. Nilai ini lebih besar dari 0,6, ini berarti kuesioner dari hasil penelitian ini reliabel. Dan hasil ini berarti reliabilitas pada penelitian ini baik karena berada pada range 0,8-1.

\section{Hasil uji normalitas}

Uji normalitas pada penelitian ini menggunakan metode Shapiro Wilk yang dihitung menggunakan bantuan dari program terapan. Data dianggap mempunyai distribusi normal apabila mempunyai nilai signifikansi lebih besar dari 0,05. Hasil Uji normalitas telah direkap dan dapat dilihat pada tabel 5 berikut.

Tabel 5. Hasil uji normalitas

\begin{tabular}{|c|c|c|c|c|c|c|}
\hline \multicolumn{7}{|c|}{ Tests of normality } \\
\hline & \multicolumn{3}{|c|}{ Kolmogorov-Smirnov ${ }^{a}$} & \multicolumn{3}{|c|}{ Shapiro-Wilk } \\
\hline & Statistic & $d f$ & Sig. & Statistic & $d f$ & Sig. \\
\hline Unstandardized residual &, 130 & 30 &, $200^{*}$ & ,948 & 30 &, 148 \\
\hline \multicolumn{7}{|c|}{ *. This is a lower bound of the true significance. } \\
\hline a. Lilliefors Significanc & rection & & & & & \\
\hline
\end{tabular}

Hasil uji normalitas yang tertera pada tabel 5 menunjukkan nilai signifikansi shapiro wilk sebesar 0,148 yang lebih besar dari 0,05 dan dapat ditarik kesimpulan bahwa data pada kuesioner berdistribusi normal

\section{Analisis korelasi}

Analisis korelasi pada penelitian ini menggunakan metode Pearson Product Moment yang dihitung menggunakan bantuan dari program terapan dapat dilihat pada tabel 6 dan tabel 7 .

Tabel 6. Korelasi variabel penerapan SMK3 dan tingkat kecelakaan

\begin{tabular}{lll}
\hline & & \multicolumn{1}{c}{ Korelasi signifikan } \\
\hline Var & $\mathrm{r}$ & Keterangan \\
\hline X23 & 0,568 & Ketersediaan rambu-rambu tanda bahaya pada perusahaan \\
\hline X9 & 0,556 & Perusahaan harus memberikan pelatihan K3 secara rutin \\
\hline X32 & 0,539 & Perusahaan harus melakukan tinjauan ulang SMK3 secara berkala \\
\hline X2 & 0,513 & $\begin{array}{l}\text { Perusahaan harus memiliki prosedur yang tepat dalam menangani } \\
\text { kecelakaan kerja }\end{array}$ \\
\hline X10 & 0,506 & $\begin{array}{l}\text { Perusahaan harus memiliki prosedur yang tepat dalam mengidentifikasi } \\
\text { masalah yang berhubungan dengan K3 }\end{array}$ \\
\hline X33 & 0,485 & Perusahaan selalu memiliki inovasi baru untuk meningkatkan kualitas K3 \\
\hline X25 & 0,449 & Inspeksi rutin staff K3 kepada para pekerja \\
\hline X3 & 0,447 & $\begin{array}{l}\text { Perusahaan memastikan semua pekerja memiliki pengetahuan pada } \\
\text { kebijakan K3 perusahaan }\end{array}$ \\
\hline X8 & 0,429 & $\begin{array}{l}\text { Pemberian sanksi kepada pekerja yang melanggar atau tidak mentaati K3 } \\
\text { perusahaan }\end{array}$ \\
\hline X28 & 0,429 & Pelaksanaan rapat evaluasi K3 secara rutin \\
\hline X16 & 0,427 & Pemeriksaan kesehatan secara berkala kepada pekerja \\
\hline X31 & 0,407 & Memperbarui APD yang sudah usang dan tidak layak pakai. \\
\hline X11 & 0,406 & Perusahaan harus menyediakan asuransi kesehatan kepada pekerja \\
\hline X19 & 0,385 & Mempunyai hubungan yang baik dan erat dengan pihak asuransi \\
\hline
\end{tabular}


Tabel 7 Variabel yang tidak berkorelasi antara penerapan SMK3 dan tingkat kecelakaan

\begin{tabular}{|c|c|c|}
\hline \multicolumn{3}{|r|}{ Korelasi tidak signifikan } \\
\hline Var & $\mathrm{r}$ & Keterangan \\
\hline X5 & 0,356 & Semua pihak memastikan bahwa K3 adalah tanggung jawab bersama \\
\hline $\mathrm{X} 4$ & 0,350 & $\begin{array}{l}\text { Perusahaan harus memiliki prosedur penggunaan peralatan dan } \\
\text { perlengkapan keselamatan kerja }\end{array}$ \\
\hline $\mathrm{X} 30$ & 0,336 & $\begin{array}{l}\text { Tindakan penanggulangan kecelakaan kerja sudah dilakukan dengan } \\
\text { baik oleh pekerja }\end{array}$ \\
\hline $\mathrm{X} 29$ & 0,328 & Pencatatan insiden, kondisi atau kecelakaan kerja \\
\hline X34 & 0,321 & $\begin{array}{l}\text { Perusahaan harus membuat buku catatan masa pakai APD dan } \\
\text { menyiapkan APD pengganti bila akan habis masa pakainya }\end{array}$ \\
\hline X6 & 0,283 & Perusahaan akan bertanggung jawab jika terjadinya kecelakaan kerja \\
\hline $\mathrm{X} 14$ & 0,280 & Penyediaan APD yang lengkap dan alat pemadam kebakaran \\
\hline $\mathrm{X} 18$ & 0,279 & Penyimpanan catatan kesehatan setiap pekerja \\
\hline $\mathrm{X} 7$ & 0,228 & $\begin{array}{l}\text { Pemberian reward pada pekerja yang menerapkan K3 perusahaan } \\
\text { dengan baik }\end{array}$ \\
\hline $\mathrm{X} 21$ & 0,200 & $\begin{array}{l}\text { Promosi yang rutin tentang pentingnya K3 pada papan pengumuman } \\
\text { perusahaan }\end{array}$ \\
\hline $\mathrm{X} 22$ & 0,184 & $\begin{array}{l}\text { Perusahaan harus memberikan reaksi yang tepat dan cepat jika terjadi } \\
\text { insiden atau suatu kondisi darurat }\end{array}$ \\
\hline $\mathrm{X} 26$ & 0,151 & Pekerja merapikan prasarana dan peralatan kerja sesudah digunakan \\
\hline X13 & 0,083 & $\begin{array}{l}\text { Perusahaan harus memiliki ahli K3 hukum yang memiliki lisensi ahli } \\
\text { K3 }\end{array}$ \\
\hline $\mathrm{X} 1$ & 0,063 & Perusahaan harus memiliki buku panduan pelaksanaan K3 \\
\hline $\mathrm{X} 15$ & 0,002 & Pekerja membuang sampah dan sisa material ke tempat sampah \\
\hline
\end{tabular}

Pada tabel 6 dan tabel 7 dapat dilihat dari 29 variabel penerapan SMK3 yang sudah ditentukan sebelumnya terdapat 15 variabel yang tidak berkorelasi terhadap variabel tingkat kecelakaan dimana nilai $r$ hitung yang didapat dari program terapan nilainya dibawah $r$ tabel yaitu 0,361 , dan terdapat 14 variabel yang berkorelasi terhadap variabel tingkat kecelakaan, dimana nilai $r$ hitung lebih besar dari $r$ tabel $(0,361)$. Variabel yang berkorelasi paling tinggi terhadap tingkat kecelakaan adalah variabel X23 pada penerapan dan pelaksanaan SMK3 yaitu ketersediaan ramburambu tanda bahaya pada perusahaan yang memiliki nilai r 0,568 atau berkorelasi sedang. Semua hasil dari analisis korelasi yang berkorelasi memiliki nilai yang positif, yang berarti memiliki hubungan yang positif antara variabel penerapan SMK3 dan variabel tingkat kecelakaan, yaitu nilai variabel penerapan SMK3 berbanding lurus dengan variabel tingkat kecelakaan. Urutan variabel yang paling berhubungan ini diambil berdasarkan nilai $r$ hitung yang nilainya dari yang terbesar ke yang terkecil, yaitu:

a. Variabel X23, yaitu ketersediaan rambu-rambu tanda bahaya pada perusahaan, yang termasuk ke penerapan dan pelaksanaan SMK3.

b. Variabel X9, yaitu perusahaan harus memberikan pelatihan K3 secara rutin, yang termasuk ke perencanaan SMK3.

c. Variabel X32, yaitu perusahaan harus melakukan tinjauan ulang SMK3 secara berkala yang termasuk ke evaluasi SMK3.

d. Variabel X2, yaitu perusahaan harus memiliki prosedur yang tepat dalam menangani kecelakaan kerja, yang termasuk ke perencanaan SMK3.

e. Variabel X10, yaitu perusahaan harus memiliki prosedur yang tepat dalam mengidentifikasi masalah yang berhubungan dengan K3, yang termasuk ke perencanaan SMK3.

f. Variabel X33, yaitu perusahaan selalu memiliki inovasi baru untuk meningkatkan kualitas K3 yang termasuk ke evaluasi SMK3.

g. Variabel X25, yaitu inspeksi rutin staff K3 kepada para pekerja, yang termasuk ke penerapan dan pelaksanaan SMK3.

h. Variabel X30, yaitu perusahaan memastikan semua pekerja memiliki pengetahuan pada kebijakan K3 perusahaan yang termasuk ke evaluasi SMK3.

i. $\quad$ Variabel X8, yaitu pemberian sanksi kepada pekerja yang melanggar atau tidak mentaati K3 perusahaan, yang termasuk ke perencanaan SMK3. 
j. $\quad$ Variabel X28, yaitu pelaksanaan rapat evaluasi K3 secara rutin yang termasuk ke evaluasi SMK3.

k. Variabel X16, yaitu pemeriksaan kesehatan secara berkala kepada pekerja, yang termasuk ke penerapan dan pelaksanaan SMK3.

1. Variabel X31, yaitu memperbarui APD yang sudah usang dan tidak layak pakai, yang termasuk ke evaluasi SMK3.

m. Variabel X11, yaitu perusahaan harus menyediakan asuransi kesehatan kepada pekerja, yang termasuk ke perencanaan SMK3.

n. Variabel X19, yaitu mempunyai hubungan yang baik dan erat dengan pihak asuransi, yang termasuk ke penerapan dan pelaksanaan SMK3.

\section{KESIMPULAN DAN SARAN}

\section{Kesimpulan}

Dalam penelitian hubungan faktor penerapan SMK3 pada proyek konstruksi, maka dapat diambil kesimpulan sebagai berikut:

1. Dari hasil analisis menggunakan program terapan, terdapat 14 variabel faktor penerapan SMK3 yang berkorelasi terhadap tingkat kecelakaan. 14 faktor penerapan ini diambil berdasarkan nilai $r$ hitung yang lebih besar $r$ tabel, $r$ tabel pada penelitian adalah sebesar 0,361. Urutan variabel yang berkorelasi ini diambil berdasarkan nilai $\mathrm{r}$ hitung yang nilainya dari yang terbesar ke yang terkecil, Dari 14 variabel yang berkorelasi dengan tingkat kecelakaan ini, 4 variabel termasuk ke dalam penerapan dan pelaksanaan SMK3, 5 variabel masing-masing termasuk ke dalam perencanaan SMK3 dan evaluasi SMK3, ini menandakan bahwa ketiga faktor SMK3 tersebut sama pentingnya untuk diimplementasikan perusahaan. Semua variabel independen yang berkorelasi ini memiliki nilai positif, yang berarti variabel independennya $(\mathrm{X})$ berbanding lurus dengan variabel dependennya $(\mathrm{Y})$.

2. Faktor penerapan SMK3 yang paling berhubungan dengan tingkat kecelakaan adalah variabel 23 yang termasuk pada penerapan dan pelaksanaan SMK3, yaitu ketersediaan rambu-rambu tanda bahaya pada perusahaan dengan nilai $r$ sebesar 0,568 yang termasuk korelasi sedang.

\section{Saran}

Dari kesimpulan diatas, beberapa saran yang dapat dilakukan untuk kedepannya adalah sebagai berikut:

1. Beberapa penerapan dapat ditingkatkan lagi, seperti menambah rambu-rambu tanda bahaya di proyek dan juga pihak safety engineer dapat memberikan pelatihan K3 secara rutin kepada para pekerja, seperti 2 minggu atau 1 bulan sekali agar para pekerja tetap bekerja dengan memperhatikan K3 yang ada.

2. Penelitian ini dapat dilakukan lebih lanjut menggunakan pekerjaan konstruksi lainnya diluar gedung, seperti pembangkit listrik, jalan, dan lain sebagainya dengan menggunakan data-data tambahan seperti data tingkat kecelakaan.

\section{DAFTAR PUSTAKA}

Ariestadi, D. Teknik Struktur Bangunan. Jakarta: Departemen Pendidikan Nasional. 2008.

Bramantya, Darma. Penerapan Sistem Manajemen Keselamatan dan Kesehatan Kerja di Lingkungan Proyek Pembangunan Midtown Hotel Samarinda. Universitas 17 Agustus 1945 Samarinda. 2011.

Gunara, S. Buku Pedoman Pelaksanaan Keselamatan dan Kesehatan Kerja. Jakarta. 2017.

Heinrich, H. P. Industrial Accident Prevention: A Safety Management. NY: McGraw-Hill. 1980.

Hidayat, MT. Penerapan Keselamatan dan Kesehatan Kerja pada Proyek Konstruksi di Balikpapan. Skripsi. Universitas 17 Agustus 1945 Samarinda. 2011.

Hinze, J. Construction Safety. NJ: Prentice-Hall. 1997.

ILO (International Labour Organization). Occupational Safety and Health Management in the Construction Sector. 2011.

Simanjuntak, M. R. Identifikasi Penyebab Resiko Kecelakaan Kerja Pada Kegiatan Konstruksi Bangunan di DKI Jakarta. Jurnal Ilmiah Media Engineering. 2012. 
